\title{
BMJ Open Adolescents and age of consent to HIV testing: an updated review of national policies in sub-Saharan Africa
}

\author{
Magdalena Barr-DiChiara (D) , ${ }^{1}$ Mandikudza Tembo, ${ }^{2,3}$ Lisa Harrison, ${ }^{4}$ \\ Caitlin Quinn, ${ }^{1}$ Wole Ameyan, ${ }^{1}$ Keith Sabin, ${ }^{5}$ Bhavin Jani, ${ }^{6}$ Muhammad S Jamil, ${ }^{1}$ \\ Rachel Baggaley, ${ }^{1}$ Cheryl Johnson ${ }^{1}$
}

To cite: Barr-DiChiara $\mathrm{M}$, Tembo M, Harrison L, et al. Adolescents and age of consent to HIV testing: an updated review of national policies in sub-Saharan Africa. BMJ Open 2021;11:e049673. doi:10.1136/ bmjopen-2021-049673

- Prepublication history and additional supplemental material for this paper are available online. To view these files, please visit the journal online (http://dx.doi.org/10.1136/ bmjopen-2021-049673).

Received 25 March 2021 Accepted 29 June 2021

Check for updates

(C) Author(s) (or their employer(s)) 2021. Re-use permitted under CC BY. Published by BMJ.

${ }^{1}$ Global HIV, Hepatitis and STI Programmes, World Health Organization, Geneva, Switzerland

${ }^{2}$ Department of Infectious Disease Epidemiology, London School of Hygiene and Tropical Medicine, London, UK ${ }^{3}$ Biomedical Research and Training Institute, Harare, Zimbabwe

${ }^{4}$ South West Screening and Immunisations, Public Health England, London, UK

${ }^{5}$ Strategic Information and Evaluation, UNAIDS, Geneva,

Switzerland

${ }^{6}$ World Health Organization, Dar es Salaam, Tanzania

Correspondence to Magdalena Barr-DiChiara; m.dichiara@gmail.com

\section{ABSTRACT}

Objectives In sub-Saharan Africa (SSA) where HIV burden is highest, access to testing, a key entry point for prevention and treatment, remains low for adolescents (aged 10-19). Access may be hampered by policies requiring parental consent for adolescents to receive HIV testing services (HTS). In 2013, the WHO recommended countries to review HTS age of consent policies. Here, we investigate country progress and policies on age of consent for HIV testing.

Design Comprehensive policy review.

Data sources Policies addressing HTS were obtained through searching WHO repositories and governmental and non-governmental websites and consulting country and regional experts.

Eligibility criteria HTS policies published by SSA governments before 2019 that included age of consent. Data extraction and synthesis Data were extracted on HTS age of consent including exceptions based on risk and maturity. Descriptive analyses of included policies were disaggregated by Eastern and Southern Africa (ESA) and Western and Central Africa (WCA) subregions.

Results Thirty-nine policies were reviewed, 38 were eligible; $19 / 38$ (50\%) permitted HTS for adolescents $\leq 16$ years old without parental consent. Of these, six allowed HTS at $\geq 12$ years old, two at $\geq 13$, two at $\geq 14$, five at $\geq 15$ and four at $\geq 16$. In $E S A, 71 \%(n=15 / 21)$ allowed those of $\leq 16$ years old to access HTS, while only $24 \%(n=6 / 25)$ of WCA countries allowed the same. Maturity exceptions including marriage, sexual activity, pregnancy or key population were identified in 18 policies. In $2019,63 \%$ $(n=19 / 30)$ of policies with clear age-based criteria allowed adolescents of 12-16 years old to access HIV testing without parental consent, an increase from $37 \%(n=14 / 38)$ in 2013.

Conclusions While many countries in SSA have revised their HTS policies, many do not specify age of consent. Revision of SSA consent to HTS policies, particularly in WCA, remains a priority to achieve the 2025 goal of $95 \%$ of people with HIV knowing their status.

\section{BACKGROUND}

In the past decade, substantial but unequal progress has been made towards the global '90-90-90' fast-track goals: in 2019, an estimated $81 \%$ of people living with HIV (PLHIV)

\section{Strengths and limitations of this study}

This study provides a comprehensive review of national age of consent to HIV testing policies in subSaharan Africa.

- This review included national policy documents but did not assess national laws, which contribute to a potentially limiting operational context to better understand guidance, which informs routine implementation

- Due to varied document formats, the reviewers employed a non-automatised data extraction that was complemented by using key words to maintain repeatability.

- Despite a robust search approach, some policy documents may not have been identified.

know their status, $82 \%$ of aware PLHIV are on antiretroviral therapy (ART) and $88 \%$ of PLHIV on ART are achieving viral suppression. ${ }^{1}$ Despite successes, nearly $19 \%$ of the 38 million PLHIV remain undiagnosed and there are an estimated 1.7 million new HIV infections annually. ${ }^{2}$

Globally, three-quarters (approximately 130000 ) of the new 170000 annual HIV infections among adolescents (aged 10-19 years) are in girls. ${ }^{3}$ In sub-Saharan Africa (SSA), home to nearly $90 \%$ of all adolescents and young PLHIV, adolescent girls and young women aged 15-24 years make up one-quarter (about 330 000) of the new HIV infections although they represent just $10 \%$ of the population. ${ }^{2}$ The number of young people in SSA is rapidly increasing, and it is estimated that there will be almost 500 million 15-24 year olds in the region by $2055 .^{2}$ Recent projections point to declines in HIV infections among young people in SSA but not enough to reach global targets for low HIV incidence by $2030 .^{24}$

Despite the high burden and incidence and growing population, access to and uptake of 
HIV testing services (HTS), a pathway to essential prevention and treatment, remains remarkably low among adolescents. ${ }^{5}{ }^{6}$ In Eastern and Southern Africa (ESA), it is estimated that only $27 \%$ of adolescent girls and $16 \%$ of adolescent boys aged 15-19 years old received an HIV test in 2019, and lower uptake was observed in Western and Central Africa (WCA). ${ }^{3}$ Access may be hampered by policies requiring parental consent for adolescents to receive HTS. $^{7-9}$

Adolescence is a time of rapid physical, sexual and cognitive development. Health services for adolescents, including HTS, should be delivered through youth-friendly approaches that reflect their diverse and evolving needs. ${ }^{10}$ Social determinants, such as wealth and gender inequality as well as access to health and education services, impact adolescent health behaviour and outcomes in the near term, as they transition into adulthood and throughout the life course. ${ }^{11-14}$

Particularly underserved are adolescents and young people from key populations: men who have sex with men, transgender people, young people who sell $\operatorname{sex}^{i}$ (people 10-24 years of age, including children 10-17 years old who are sexually exploited and adults 18-24 years old who are sex workers), people who inject drugs and people in prisons or closed settings. Key populations, especially those of younger ages, are criminalised and face stigma and discrimination from community members and providers. ${ }^{15-17}$

Adolescents at high ongoing risk who do not know their HIV status can benefit from HTS, prevention or treatment, but access to these services is limited by policies requiring authorisation from a parent or guardian. ${ }^{7-9} 18$ While parental support can have a positive effect on adolescent's sexual health decision-making, for many adolescents who fear disclosing their sexual and other risk behaviours to their parents, those who do not have positive parental relationships or those who live in child-headed households, parental consent requirements pose a major barrier to HTS. ${ }^{19}$ Empowering adolescents to freely access HTS and to choose how they want to test, including to use HIV self-testing (HIVST), supports equitable service delivery and the right to access health services. ${ }^{20-22}$ Earlier analysis of the relationship between HTS coverage of young people in SSA and age of consent policies showed that allowing free adolescent access was associated with testing coverage of 14.0 percentage points

\footnotetext{
${ }^{\mathrm{i}}$ While young adults who sell sex are considered sex workers, multiple international conventions describe the participation of those under 18 years of age in selling sex as a contravention of human rights law, and those who do so are considered sexually exploited. United Nations. United Nations Convention on the Rights of the Child (Article 1). U.N. Doc. A/Res/44/25, 1989 (http://www.ohchr.org/EN/ProfessionalInterest/Pages/CRC.aspx United Nations. United Nations protocol to prevent, suppress, and punish trafficking in persons, especially women and children. Supplementing the United Nations convention against transnational organised crime. Article 3 (a-d); 2001 (A/45/49, https:// www.unodc.org/documents/treaties/UNTOC/Publications/TOCConvention/TOCebook-e.pdf.
}

higher for girls and 6.9 percentage points for boys. ${ }^{8}$ In 2013, WHO guidance on HIV and adolescents encouraged countries to consider revising parental consent requirements to reduce barriers to HTS. ${ }^{23}$ Since that time, the WHO has recommended HIVST, a convenient and private option, which has been demonstrated highly acceptable for adolescents in SSA. ${ }^{24}{ }^{25}$ Countries in SSA have moved to rapidly introduce and scale up differentiated HIVST approaches that link people to diagnosis, treatment and care. Recent findings show that when given the option of facility-based HTS or HIVST, adolescents and young people choose HIVST over conventional modalities and are more likely to test and share tests with peers and partners when using HIVST. ${ }^{26} 27$

Here, we review policies in force following the WHO 2013 guidelines to evaluate country progress and uptake of WHO guidance on age of consent for HIV testing, including the age of consent for accessing HIVST. ${ }^{72} 28$

\section{METHODS}

\section{Search strategy}

We carried out a search of national policy documents related to HTS through searching WHO repositories, governmental and non-governmental websites and search engines and contacting WHO country contacts and regional experts through April 2018 and updated our database through August 2020 (online supplemental file 1$){ }^{29}$

\section{Inclusion criteria}

All national policy documents pertaining to HTS were included: national HIV guidelines and strategic plans covering HIV and integrated guidelines on the prevention, treatment and care of HIV. For inclusion in the review, the policy must have included adolescent consent to HIV testing and be published by a WHO member state in SSA, of which there were 49 . The policy language was not restricted, but in policies other than English, extraction of age of consent was prioritised. The date of publication was not restricted, and when more than one policy were identified for a country, the most current publication was included. When necessary, we contacted government officials, regional technical advisors and other key experts to gather and/or validate information.

\section{Data extraction}

Policy data were extracted using a standardised Excelbased form (see online supplemental file 2, policy data extraction tool). Information extracted included age of consent to HIV testing and/or self-testing as well as exceptions, including but not limited to individual maturity, key population status, emancipation, parenthood, marital status, sexual activity and year of publication. HIV burden for included countries was classified as high $(\geq 5 \%)$ or low $(<5 \%)$ and collected from the Global AIDS Monitoring tool. ${ }^{18}$ In addition to the policy assessment by the review team, national age of consent to HTS was 
Table 1 Definitions for country policies to age of consent to HIV testing

\begin{tabular}{|c|c|}
\hline Policy category & Definition \\
\hline No mention (NM) & Policy does not mention adolescents or minors or age of consent for HTS \\
\hline Minor not defined (MND) & Age of minor not defined \\
\hline $\begin{array}{l}\text { Some adolescents may access } \\
\text { without parental consent (SAC) }\end{array}$ & $\begin{array}{l}\text { Age of consent to HIV testing is below } 18 \text { years. Minimum age to consent for HTS varies } \\
\text { by country. Ability to consent is defined by age }\end{array}$ \\
\hline
\end{tabular}

HTS, HIV testing services.

also obtained from the National Commitments and Policy Instrument (NCPI) database, a global survey of HIV laws and policies. ${ }^{28}$ Policies in languages other than English were reviewed with the aid of the translation software Google Translate.

Two authors (MB-D and MT) extracted information from policy documents independently.

Key word searching for terms including adolescent, child, minor, parent and consent was used to identify content addressing age of consent with full-text review completed on the sections identified through this process. Disagreements between reviewers were resolved by discussion and consultation with a senior author $(\mathrm{CJ})$.

\section{Analysis}

Countries were classified according to two subregions: ESA and WCA. ${ }^{\text {ii }}$ Policy data were then categorised using previously developed definitions and categories (table 1): no mention, no adolescent access without parental consent, some adolescents may access without parental consent and no minimum age limit. ${ }^{8}$

We conducted a descriptive analysis, complementing 2019 policy data with results reported in NCPI. We assessed country policy changes since 2013 , including variation in age of consent to HIV testing and maturity exceptions, by comparing our results to the previous WHO review on age of consent. $^{17}$

\footnotetext{
${ }^{\mathrm{ii}}$ We present data in two subregions, ESA and WCA, which closely align with UNAIDS regions. We include Djibouti and Somalia, which are not in these UNAIDS regions. We do not include Algeria, which is traditionally North Africa, though it sits in the WHO African region.
}

\section{Patient and public involvement}

Patients and/or the public were not involved in the design, conduct or reporting of this research.

\section{RESULTS}

A total of 39 national policies published from 2005 to 2019 were identified among SSA countries; for ten countries, no policy was identified. Of these, $1 / 39(<3 \%)$ did not mention consent for adolescents or minors. Thirtyeight policies described consent for HTS and maturity exceptions and were included in the analysis: 10 policies did not provide definition of a minor, one did not use age-based criteria for consent and 27 policies detailed age-based of consent criteria (see online supplemental file 3, included policies). Among included policies, eight limited HTS access without parental consent to persons $\geq 18$ years of age, while $19(50 \%)$ permitted HTS for adolescents $<18$ years old without parental consent. Of these, six allowed HTS at $\geq 12$ years old, two at $\geq 13$, two at $\geq 14$, five at $\geq 15$ and four at $\geq 16$ (table 2 ).

The minimum age of consent was 12 years, reported in six countries, most of which were high burden (Lesotho, Mozambique, Rwanda, South Africa, Eswatini and Uganda) (table 2).

Among high-burden countries, $80 \%(n=8 / 10)$ allowed younger adolescents to access testing independent of parents/guardians (Botswana, NA; Eswatini, 12; Lesotho, 12; Malawi, 13; Mozambique, 1; Namibia, 14; South Africa, 12; and Uganda, 12), while 20\% ( $\mathrm{n}=2 / 10)$ limited independent consent to older adolescents (Zambia, 16, and Zimbabwe, 16) (table 3). 
Table 2 Age of consent to HTS policies in sub-Saharan Africa

National policies reviewed $(n=49)$ (categories not mutually exclusive)

No. of countries (\%)

Policy existing for HTS, age of consent clearly defined (including no age limit) $30(61.2 \%)$

Policy existing for HTS but no age of consent specified ${ }^{\star}$

$8(16.3 \%)$

Total number of countries with policies discussing age of consent to HTS $38(77.6 \%)$

Policy existing for HTS but no mention of 'adolescent' or 'minor'

$1(2.0 \%)$

No policy for HTS $10(20.4 \%)$

Total number of countries either without HTS policies or that have policies that do not mention adolescents or minors

National age of consent to HTS $(n=38)$

The year following the country indicates the year of publication for national policy.

Age of minor not defined

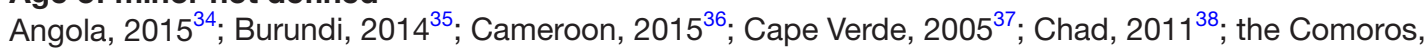
200739; DRC, 2017 ${ }^{40}$; Guinea, 2018 ${ }^{41}$; Nigeria, 2016 ${ }^{42}$; Sudan, $2016^{43}$

No age limit-all or most adolescents eligible $\dagger$
Botswana, $2016^{44}$
12 years
Lesotho, 2016
Uganda, $2016^{50}$

The Gambia, 2014 ${ }^{51}$; Malawi, $2016^{52}$

\section{4 years}

Liberia, 2015 ${ }^{53}$; Namibia, $2016^{54}$

\begin{tabular}{|c|c|}
\hline $\begin{array}{l}15 \text { years } \\
\text { Ethiopia, } 2017^{55} \text {; Kenya, 2015 } 56 \text {; Senegal, } 2017^{57} \text {; Somalia, } 2017^{58} \text {; United Republic of Tanzania, } 2019^{59}\end{array}$ & $5(13.2 \%)$ \\
\hline 16 years & 4 (10.5\%) \\
\hline
\end{tabular}

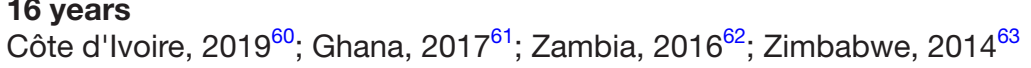

\section{8 years \\ Benin, 201764; Burkina Faso, 2008 ${ }^{65}$; Central African Republic, $2010^{66}$; Eritrea, 201967; Madagascar,} 2011 ${ }^{68}$; Mali, 2017 69 ; Sierra Leone, 2017 ${ }^{70}$; South Sudan, $2017^{71}$

*These countries used the term 'minor' in their guidance, but do not specify an age.

†These countries stipulate considerations other than age to allow access to HTS (eg, shows maturity; of reproductive age; or married, pregnant or engaged in behaviour that would put them at risk).

DRC, Democratic Republic of the Congo; HTS, HIV testing services.

All high-burden country policies reviewed permitted adolescents of 16 years old and younger to access HTS without parental consent pointing to alignment with WHO 2013 guidance and movement towards accessible testing services for adolescents where HIV is a major public health threat. NCPI age of consent policy reporting complemented our findings; however, some instances of disagreement were identified (table 4).

\section{Maturity exceptions}

Maturity exceptions that waive parental consent requirements and effectively lower the age of consent for some groups of minors were identified in more than half $(n=20 / 38)$ of policies that address age of consent, including those policies that did not specify age-based definitions of the age of majority (table 5).

The most common maturity exceptions were pregnancy $(\mathrm{n}=15 / 38)$, demonstrated maturity and understanding of test $(n=13 / 38)$, marriage $(n=11 / 38)$, parenthood $(\mathrm{n}=10 / 38)$ and being at risk of contracting HIV due to behaviours or population group $(\mathrm{n}=9 / 38)$. Only six countries (Liberia, Rwanda, Sierra Leone, Somalia, South Sudan and Zambia) include maturity exceptions for adolescents from key populations group, all related to people who sell sex. Only one country (Liberia) included a maturity exception for street children. One country (Botswana) does not use age to determine adolescent access to HIV testing. Instead, the policy emphasised the need for providers to assess client maturity and client risks.

When stratified by subregion, we identified notable differences the age of consent policies between ESA $(\mathrm{n}=21$ countries $)$ and WCA $(\mathrm{n}=25$ countries) subregions. In WCA, for $32 \%$ of countries $(n=8 / 25)$, no HTS policy was identified (Congo, Equatorial Guinea, Gabon, Guinea-Bissau, Mauritania, Niger, São Tomé and Príncipe, Seychelles and Togo). While in ESA, only two countries (Seychelles and Djibouti) had no identified policy. 
Table 3 HIV testing policies identified and age of consent to HTS in sub-Saharan Africa

\begin{tabular}{|c|c|c|c|c|}
\hline & Country & Age of consent to HTS & Sub-region & HIV burden* \\
\hline 1 & Angola & $\mathrm{MND}^{34}$ & ESA & Low \\
\hline 2 & Benin & 18 (Age 15 if adolescent shows maturity) $^{64}$ & WCA & Low \\
\hline 3 & Botswana & $\mathrm{NA}^{44}$ & ESA & High \\
\hline 4 & Burkina Faso & 18 (MME: from 15 years of age.) ${ }^{65}$ & WCA & Low \\
\hline 5 & Burundi & $\mathrm{MND}^{72}$ & WCA & Low \\
\hline 6 & Cameroon & MND (MME: HTS from age 10-13 with parental & WCA & Low \\
\hline
\end{tabular}

consent and HTS from age 14-19 if sexually active or family head) ${ }^{36}$

$\begin{array}{lll}7 & \text { Cape Verde } & \text { MND }^{37} \\ 8 & \text { Central African Republic } & 18 \text { (MME: if there is no parent or guardian and a child } \\ & & \text { is able to manage the decision, a minor may access } \\ & \text { HTS independently) })^{66}\end{array}$

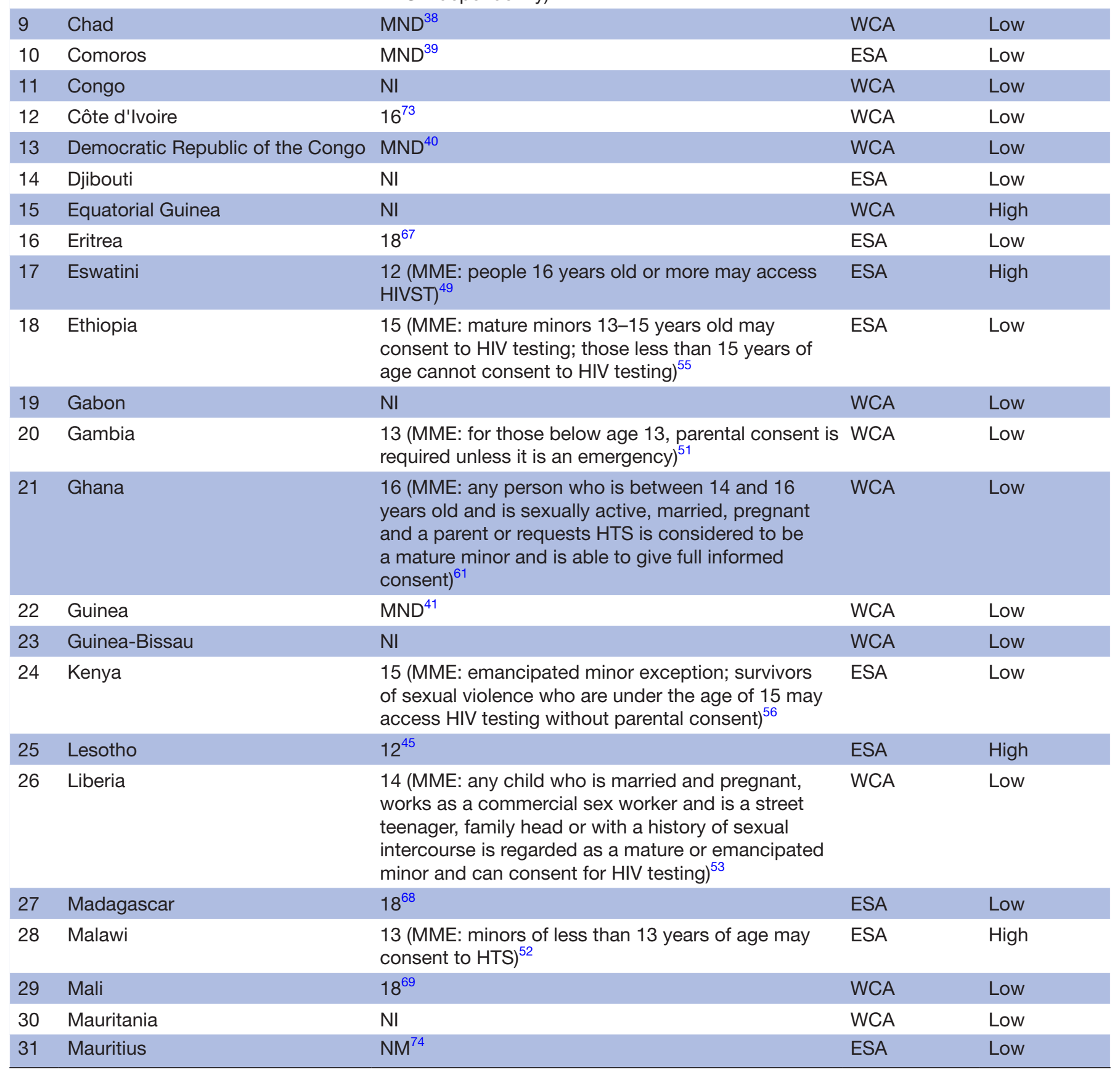


Table 3 Continued

\begin{tabular}{|c|c|c|c|c|}
\hline & Country & Age of consent to HTS & Sub-region & HIV burden* \\
\hline 32 & Mozambique & $\begin{array}{l}12 \text { (MME: adolescents married, living as if married, } \\
\text { sexually active and head of household may give } \\
\text { consent for HIV testing) }\end{array}$ & ESA & High \\
\hline 33 & Namibia & $14^{54}$ & ESA & High \\
\hline 34 & Niger & $\mathrm{NI}$ & WCA & Low \\
\hline 37 & São Tomé and Príncipe & $\mathrm{NI}$ & WCA & Low \\
\hline 38 & Senegal & $15^{57}$ & WCA & Low \\
\hline 39 & Seychelles & $\mathrm{NI}$ & ESA & Low \\
\hline 40 & Sierra Leone & $\begin{array}{l}18 \text { (MME: child survivors of sexual assault or abuse, } \\
\text { married young people under age } 18, \text { pregnant, } \\
\text { parents, minors engaged in behaviour that puts them } \\
\text { at risk and child sex workers) }\end{array}$ & WCA & Low \\
\hline 42 & South Africa & $\begin{array}{l}12 \text { (for HIVST, children between age } 12 \text { and } 18 \text { years } \\
\text { should use directly assisted testing options) }{ }^{48}\end{array}$ & ESA & High \\
\hline 43 & South Sudan & $\begin{array}{l}18 \text { (MME: married, pregnant, parents and } \\
\text { emancipated) }\end{array}$ & ESA & Low \\
\hline 44 & Sudan & MND (MME: adolescent KP†) ${ }^{43}$ & ESA & Low \\
\hline 45 & Togo & $\mathrm{NI}$ & WCA & Low \\
\hline 46 & Uganda & $12^{50}$ & ESA & High \\
\hline 47 & United Republic of Tanzania & $15^{5975}$ & ESA & Low \\
\hline 48 & Zambia & $16^{62}$ & ESA & High \\
\hline
\end{tabular}

${ }^{*}$ Countries were classified as low and high HIV burden using an HIV prevalence threshold of 5\%. Data were obtained from Global AIDS Monitoring, 2020. ${ }^{1}$

†KP, key populations

ESA, Eastern and Southern Africa; HIVST, HIV self-testing; HTS, HIV testing services; MME, mature minor exceptions; MND, minor not defined; NA, no age of consent to HTS described in policy; NI, no information; NL, no age of consent to sex law; NM, no mention; WCA, Western and Central Africa.

Of the 17 WCA countries for which a policy was identified, $70 \%(\mathrm{n}=12 / 17)$ included clearly defined age of consent for HTS, and five countries (Benin, Burkina Faso, Central African Republic, Mali and Sierra Leone) required parental consent for adolescents under 18 years of age to test. In ESA, there were six countries with an age of consent of 12 years, whereas none were identified in WCA.

Changes in age of consent policies for HIV testing over time Thirty-one of the country policies included (table 2) were published after the 2013 release of WHO guidance on HIV and adolescents, which called on policy-makers to detail clear and specific age-based consent language permitting adolescent access to HTS. ${ }^{23}$ In 2013, clear agebased criteria for consent to HTS were present in $70 \%$ $(n=28 / 40)$ of the laws and policies reviewed; we identified a similar proportion of policies with clear age-based consent language in $2019,73 \%(\mathrm{n}=28 / 38) .{ }^{7}$ We observed an increase in the proportion of policies with age-based consent criteria, which permitted adolescents of 16 years or younger to access HTS without parental consent: in 2013, 50\% ( $\mathrm{n}=14 / 28)$ allowed access without parental consent to those of 16 years or younger, and in $2019,68 \%$ $(n=19 / 28)$ allowed access without parental consent to those of 16 years or younger. While a majority of policies had been updated since 2013, reduction in age of consent to HTS occurred in just six policies, three high-burden countries (Eswatini, Mozambique and Namibia) and just four low-burden countries (Côte d'Ivoire, the Gambia, Rwanda and United Republic of Tanzania).

\section{HIV self-testing}

No policies in the 2013 review included information on age of consent for HIVST. The first WHO recommendation on HIVST was introduced in 2016. In 2019, nearly half of $(44 \%, 17 / 38)$ national policies included selftesting, and $53 \%$ of these $(n=9 / 17)$ clearly defined age 


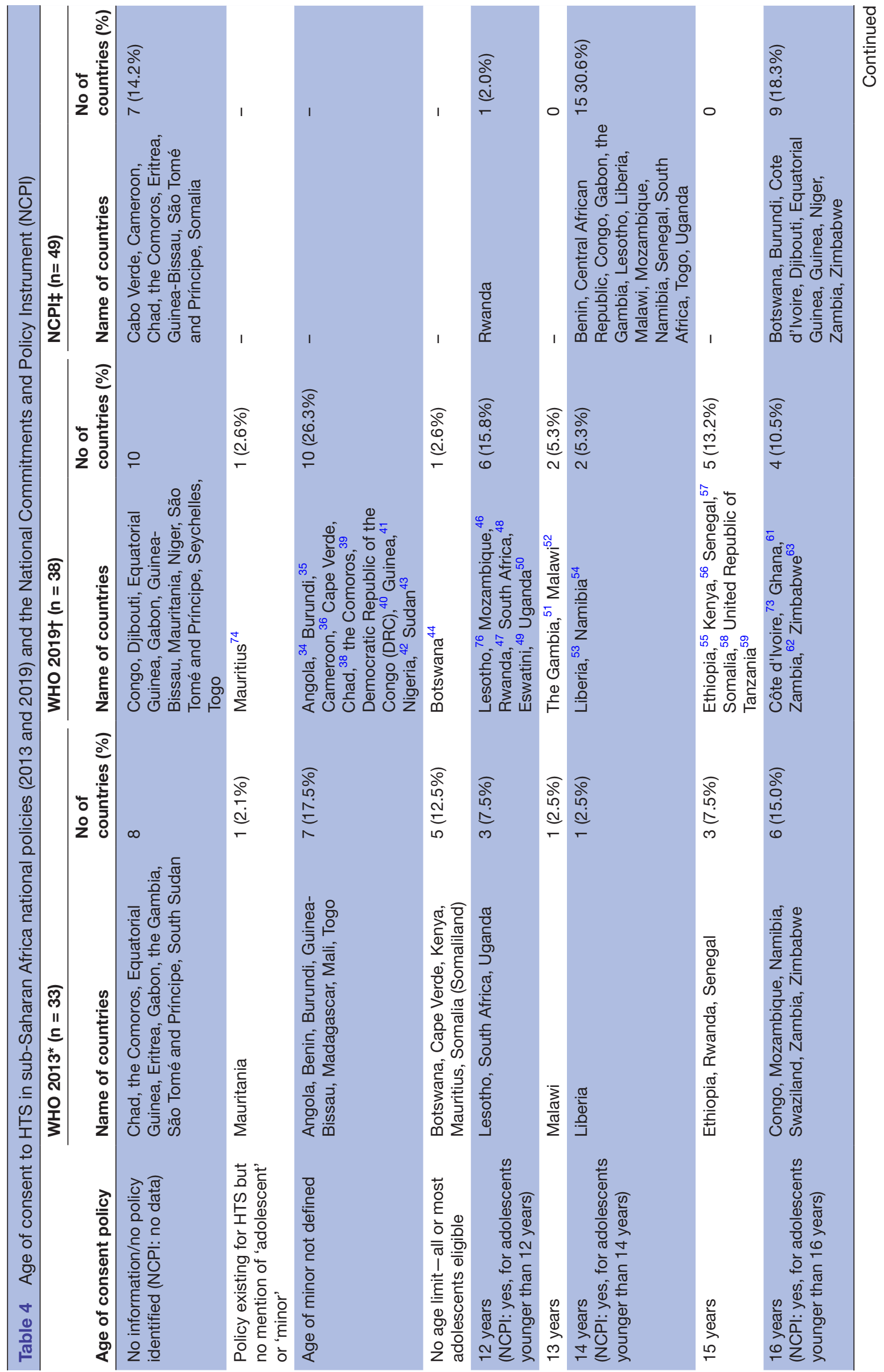




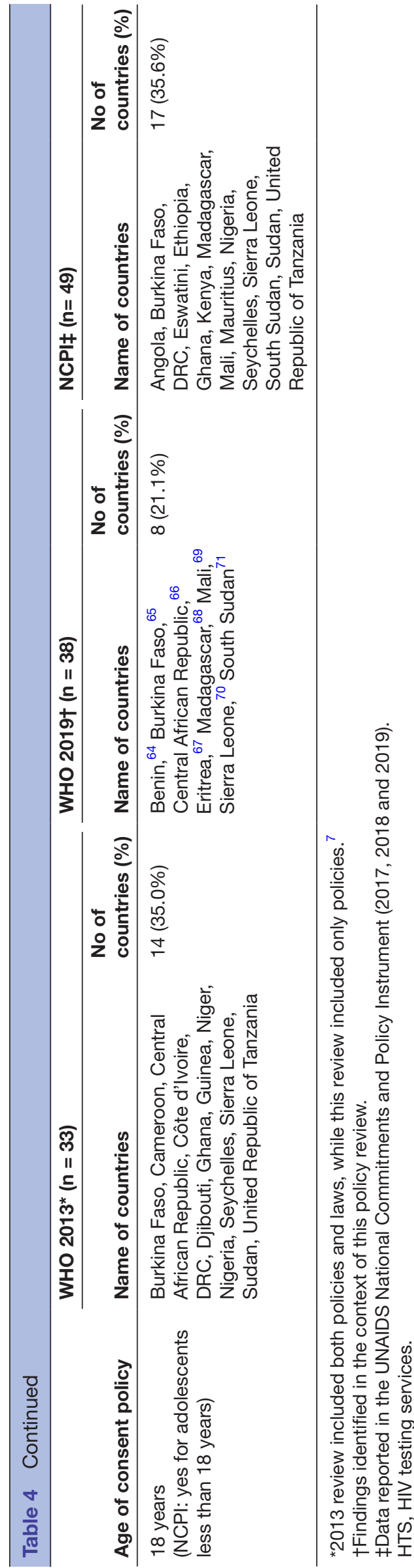

of consent for access to HIVST. Among HIVST policies, nine clearly defined age of consent for HIVST (Côte d'Ivoire, 16; Eritrea, 18; Eswatini, 16; Ghana, 16; Mali, 18; Somalia, 18; South Africa, 12 with directly assisted HIVST; South Sudan, 18; and Tanzania, 18). Nine policies (Benin, Cameroon, Democratic Republic of the Congo, Kenya, Lesotho, Malawi, Nigeria, Zambia and Zimbabwe) addressed HIVST but did not include clear definition of age of consent, and among these were two standalone HIVST policies (Zambia and Zimbabwe). HIVST policies were diverse in format; some were standalone, while others integrated HIVST into broader testing service policies. Two policies (Kenya and South Africa) explicitly enabled self-testing but only with direct assistance for those under the age of 18 years, thus distinguishing HIVST from conventional provider-delivered options. Eswatini,United Republic of Tanzania and Somalia had a higher age of consent for HIVST (16 years for Eswatini and 18 years for Somalia and United Republic of Tanzania) than for provider-delivered methods (12 years for Eswatini and 15 years for United Republic of Tanzania and Somalia).

\section{NCPI}

NCPI, a mechanism for monitoring national laws and policies, captures age of consent regulations for HIV testing and other reproductive health services among other themes. ${ }^{28}{ }^{30}$ Our review findings complement the policy reporting in NCPI but do not capture consistent country-level information on age of consent to HIV testing (table 3). The discrepancy of our findings with those reported by NCPI highlights challenges in aggregating policy information in surveys and research. Since NCPI includes age of consent policy information covering HTS, ART and sexual and reproductive health and rights (SRHR) services, it provides regular regional intelligence and offers a platform to routinely review, validate and engage around age of consent policies.

\section{DISCUSSION}

Our review found that half of policies in SSA allowed adolescents aged 16 years and younger to provide independent consent for HIV testing.

We found the minimum specified age of consent for HTS in any SSA country was 12 years with one country reporting no age-based criteria. In comparison, the minimum specified age of consent for HTS in Western Europe and North America is 14 years, with some countries reporting no age-based criteria and many countries not reporting. ${ }^{28}$ There has been substantial progress in SSA since 2013 when WHO encouraged countries to review and adapt consent policies to make HIV testing accessible to adolescents, with 31 updated policies identified. Among these, seven lowered the age of consent. ${ }^{23}$ Policy-makers in SSA have moved to address HIVST, but there is more work to be done in both developing policy and including clearly defined age of consent language. 
Table 5 Exceptions for HTS below age of consent

Exceptions for testing below stated legal age of consent

The age in parentheses indicates the national age of consent to HTS before the exception is applied

No of

countries

Shows maturity and understanding of the process and potential results (healthcare provider discretion) 13

Benin (18 years) ${ }^{64}$ Botswana (no age limit), ${ }^{44}$ Burkina Faso (18 years but 'mature minor' exception from 15

years), ${ }^{65}$ Ethiopia (15 years but 'mature minor' exception from 13 years), ${ }^{55}$ Ghana (16 years), ${ }^{61}$ Liberia (14

years), ${ }^{53}$ Malawi (13 years), ${ }^{53}$ Mozambique (12 years), ${ }^{46}$ Namibia (14 years), ${ }^{54}$ Sierra Leone (18 years),${ }^{70}$ Somalia

(15 years), ${ }^{58}$ South Africa (12 years), ${ }^{48}$ South Sudan (18 years), ${ }^{71}$ Zimbabwe (16 years) ${ }^{77}$

At risk of contracting HIV (eg, sexually active)

Burkina Faso (18 years but 'mature minor' exception from 15 years), ${ }^{65}$ Liberia (14 years), ${ }^{53}$ Namibia (14 years),${ }^{54}$

Sierra Leone (18 years), ${ }^{70}$ Somalia (15 years), ${ }^{58}$ Sudan (age of 'minor' not defined), ${ }^{43}$ United Republic of Tanzania $(15$ years $),{ }^{75}$ Zimbabwe (16 years) ${ }^{77}$

Symptomatic
Benin (18 years),${ }^{64}$ Liberia (14 years), ${ }^{53}$ Zimbabwe $(16 \text { years })^{77}$

Pregnant

Benin (18 years), ${ }^{64}$ Botswana (no age limit), ${ }^{44}$ Burkina Faso (18 years, 'mature minor' exception from 15 years) ${ }^{65}$

Cameroon (age of minor not defined), ${ }^{36}$ Ghana (16 years), ${ }^{61}$ Liberia (14 years), ${ }^{53}$ Mozambique (12 years) ${ }^{46}$

Namibia (14 years), ${ }^{54}$ Rwanda (12 years), ${ }^{47}$ Sierra Leone (18 years), ${ }^{7}$ Somalia (15 years), ${ }^{58}$ South Sudan (18

years), ${ }^{71}$ United Republic of Tanzania (15 years), ${ }^{75}$ Zambia (16 years), ${ }^{62}$ Zimbabwe (16 years) ${ }^{63}$

Parent (adolescent is already a parent)
Benin $\left(18\right.$ years) ${ }^{64}$ Botswana (no age limit) ${ }^{44}$ Cameroon (age of minor not defined) $){ }^{36}$ Ghana $\left(16\right.$ years), ${ }^{61}$
Mozambique $\left(12\right.$ years) ${ }^{46}$ Namibia (14 years),${ }^{54}$ Sierra Leone $\left(18\right.$ years), ${ }^{70}$ Somalia $\left(15\right.$ years), ${ }^{58}$ South Sudan (18
years) ${ }^{71}$ Zambia (16 years) ${ }^{62}$

Head of household

Central African Republic (18 years), ${ }^{66}$ Liberia (14 years), ${ }^{53}$ Mozambique (12 years), ${ }^{46}$ Zambia (16 years) ${ }^{62}$

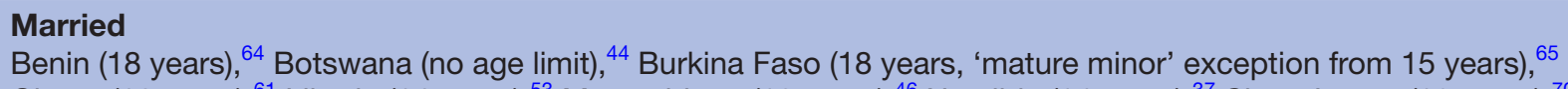

Ghana (16 years), ${ }^{61}$ Liberia (14 years), ${ }^{53}$ Mozambique (12 years), ${ }^{46}$ Namibia (14 years), ${ }^{37}$ Sierra Leone (18 years),${ }^{70}$ South Sudan (18 years), ${ }^{71}$ United Republic of Tanzania (15 years) $)^{5975}$ Zambia (16 years) ${ }^{62}$

\section{Sex workers}

Liberia (14 years), ${ }^{53}$ Rwanda (12 years), ${ }^{47}$ Sierra Leone (18 years), ${ }^{70}$ Somalia (15 years), ${ }^{58}$ South Sudan (18

years), ${ }^{71}$ Zambia (16 years) ${ }^{62}$

\section{Street children}

Liberia (14 years) $)^{53}$

\section{Emancipated minor}

Botswana (no age limit), ${ }^{44}$ Central African Republic (18 years), ${ }^{66}$ Kenya (15 years), ${ }^{56}$ Liberia (14 years), ${ }^{53}$

Madagascar (18 years), ${ }^{68}$ South Sudan (18 years $)^{71}$

.

3


self-test need tools and resources to support linkage to prevention and treatment services, and approaches that deliver self-testing to this population through assisted and unassisted methods have been demonstrated effective and acceptable in SSA. ${ }^{31}$ Two countries (South Africa and Kenya) stipulated assisted HIVST approaches for younger adolescents, thus making the modality available while ensuring a minimum standard of support for performing the self-test, interpreting the result and linking to other services.

Policies frequently included maturity exceptions that eliminate parental consent requirements for adolescents seeking HTS, including those from key populations who are at particularly high risk of HIV and may also face social and structural barriers to testing, prevention and care services. ${ }^{33}$

Many other vulnerable adolescents are left out and overlooked: only six countries (Liberia, Rwanda, Sierra Leone, Somalia, South Sudan and Zambia) have policies that address adolescents who sell sex, and exceptions for adolescents from other key populations were not identified. Exceptions did frequently address adolescent girls; those for marriage, pregnancy, involvement in sex work and sexual activity may effectively lower age of consent for some girls; however, girls may not feel empowered to seek health services or to take a test when services are not designed to be accessible to adolescents. Overall, we found great variation in maturity exceptions and are not able to ascertain how these are interpreted and put into practices by implementers and service providers or how they ultimately impact access to HIV testing for adolescents. In settings where maturity exception policies are present, programmes should assess fidelity as well as seek and consider adolescent perspectives while they aim to strengthen service delivery for HIV testing and prevention.

\section{Strengths and limitations}

Documents from nearly forty countries were reviewed using a standard approach to extraction and analysis. Despite a robust approach, some policy documents may not have been identified. Due to varied document formats, the reviewers employed a non-automatised data extraction that was complemented by using key words to maintain repeatability. This review included national policy documents but did not assess national laws, which contribute to a potentially limiting operational context to better understand guidance, which informs routine implementation. ${ }^{9}$ Since the review did not assess implementation, it does not provide insight into how policies ultimately impact HTS delivery and access for adolescents.

Further policy reviews and national assessments that address alignment on age of consent within and between HIV testing, prevention and treatment and sexually transmitted infection (STI) and other sexual and reproductive health services will illuminate opportunities to strengthen policy and implementation. Finally, while a significant proportion of policies reviewed did not define the age of consent, which limited assessment of regional trends, this did not hinder our ability to assess whether national policies contained clear description of age of consent to test.

\section{CONCLUSIONS}

Since 2013, 31 SSA countries have updated policies that include age of consent to HTS, with seven reducing the age of consent to 12 years or eliminating age-based criteria. Our findings suggest that adolescents in 19/38 $(50 \%)$ of SSA countries may access HTS without consent of a parent or guardian at varying ages: 16, 15, 14 or 12 years. Access to HTS for adolescents remains limited in WCA, where policies are fewer and older and have vague or no age of consent language. Adolescence, a period of rapid physical, sexual and cognitive development, is a time when young people need health services that address their diverse and evolving needs. HTS policies should acknowledge the right of adolescents to provide their own consent to testing, particularly through newly introduced approaches like HIVST, and be aligned with national SRHR guidance so that adolescents can receive the benefits of services for contraception, voluntary medical male circumcision, STIs, HIV prevention and antiretroviral treatment. Where adolescents have supportive parents or trusted older relatives, involving them in testing is often of great benefit to coping with a result and discussing linkage to other services post testing. As countries renew efforts to ensure that $95 \%$ of people with HIV know their status and to improve testing, prevention and treatment access for adolescents, lowering or eliminating age of consent for HIV testing should continue to be prioritised.

Correction notice This article has been corrected since it was published Online First. The funding statement has been updated.

Acknowledgements The authors thank all country and regional contacts for policies for the review.

Contributors CJ and RB devised and supervised the review. MB-D and CJ designed the protocol. MB-D conducted the search, and MT conducted the screening and data extraction. MB-D and MT qualitatively synthesised the findings and conducted descriptive analyses. MB-D and LH drafted the manuscript with input from MT, CJ and MSJ. MB-D, MT, LH, BJ, CQ, WA, MSJ, KS, RB and CJ reviewed the draft, provided critical review and read and approved the final manuscript.

Funding Funding for this review was provided by the US President's Emergency Plan for AIDS Relief (PEPFAR) through World Health Organization and USAID's Consolidated WHO Grant, Agreements US-2015-0839 and US-2016-940. This work was supported, in whole or in part, by the Bill \& Melinda Gates Foundation.

\section{Competing interests None declared.}

Patient consent for publication Not required.

Provenance and peer review Not commissioned; externally peer reviewed.

Data availability statement Data are available upon reasonable request. Data may be obtained from a third party, and some data are publicly available. Most policies included in this review are available through the following websites: (1) https://aidsfree.usaid.gov/resources/guidancedata/hts and (2) http://www. hivpolicywatch.org/database.html. If information on a policy cannot be found through these sources, please contact the authors of this review for additional information.

Supplemental material This content has been supplied by the author(s). It has not been vetted by BMJ Publishing Group Limited (BMJ) and may not have been peer-reviewed. Any opinions or recommendations discussed are solely those 
of the author(s) and are not endorsed by BMJ. BMJ disclaims all liability and responsibility arising from any reliance placed on the content. Where the content includes any translated material, BMJ does not warrant the accuracy and reliability of the translations (including but not limited to local regulations, clinical guidelines, terminology, drug names and drug dosages), and is not responsible for any error and/or omissions arising from translation and adaptation or otherwise.

Open access This is an open access article distributed in accordance with the Creative Commons Attribution 4.0 Unported (CC BY 4.0) license, which permits others to copy, redistribute, remix, transform and build upon this work for any purpose, provided the original work is properly cited, a link to the licence is given, and indication of whether changes were made. See: https://creativecommons.org/ licenses/by/4.0/.

\section{ORCID iD}

Magdalena Barr-DiChiara http://orcid.org/0000-0002-7404-7843

\section{REFERENCES}

1 UNAIDS. Global factsheet 2019. Geneva: United Nations Joint Programme on HIV/AIDS, 2020.

2 UNAIDS. Siezing the moment, tackling entrenched inequalities to end epidemics: global AIDS update 2020. Geneva: United Nations Join Programme on HIV/AIDS, 2020.

3 UNICEF. Unicef data: adolescent HIV prevention, 2020. Available: https://data.unicef.org/topic/hivaids/adolescents-young-people/

4 UNAIDS. Progress towards the start free, stay free, AIDS free targets. Geneva: United Nations Joint Programme on HIV/AIDS, 2020.

5 Wong VJ, Murray KR, Phelps BR, et al. Adolescents, young people, and the 90-90-90 goals: a call to improve HIV testing and linkage to treatment. AIDS 2017;31 Suppl 3:S191-4.

6 Kurth AE, Lally MA, Choko AT, et al. Hiv testing and linkage to services for youth. J Int AIDS Soc 2015;18:19433.

7 WHO. HIV and adolescents: guidance for HIV testing and counselling and care for adolescents living with HIV: annex 15: adolescent consent to testing: a review of current policies and issues in subSaharan Africa. Geneva: World Health Organization, 2013.

8 McKinnon B, Vandermorris A. National age-of-consent laws and adolescent HIV testing in sub-Saharan Africa: a propensity-score matched study. Bull World Health Organ 2019;97:42-50.

9 Eba PM, Lim H. Reviewing independent access to HIV testing, counselling and treatment for adolescents in HIV-specific laws in sub-Saharan Africa: implications for the HIV response. J Int AIDS Soc 2017;20:21456

10 WHO. Who recommendations on adolescent sexual and reproductive health and rights. Geneva: World Health Organization, 2018.

11 Viner RM, Ozer EM, Denny S, et al. Adolescence and the social determinants of health. Lancet 2012;379:1641-52.

12 Stoner MCD, Nguyen N, Kilburn K, et al. Age-disparate partnerships and incident HIV infection in adolescent girls and young women in rural South Africa. AIDS 2019;33:83-91.

13 Brown K, Williams DB, Kinchen S, et al. Status of HIV epidemic control among adolescent girls and young women aged 15-24 Years - Seven African Countries, 2015-2017. MMWR Morb Mortal Wkly Rep 2018;67:29-32

14 Starrs AM, Ezeh AC, Barker G, et al. Accelerate progress-sexual and reproductive health and rights for all: report of the GuttmacherLancet Commission. Lancet 2018;391:2642-92.

15 Baggaley R, Armstrong A, Dodd Z, et al. Young key populations and HIV: a special emphasis and consideration in the new who consolidated guidelines on HIV prevention, diagnosis, treatment and care for key populations. J Int AIDS Soc 2015;18:S1.

16 Cornell M, Dovel K. Reaching key adolescent populations. Curr Opin HIV AIDS 2018;13:274-80.

17 WHO. Hiv and young people who sell sex. Geneva: World Health Organization, 2015.

18 WHO. Consolidated guidelines on HIV testing services, 2019 Geneva: World Health Organization, 2019.

19 Sam-Agudu NA, Folayan MO, Ezeanolue EE. Seeking wider access to HIV testing for adolescents in sub-Saharan Africa. Pediatr Res 2016;79:838-45.

$20 \mathrm{WHO}$, Institute RT. The voices, values and preference of adolescents on HIV testing and counselling: consultation for the development of the world Health organization HIV testing and counselling guidelines for adolescents. Geneva: World Health Organization, Royal Tropical Institute, 2013.

21 United Nations Human Rights office of the High Commissioner. Convention on the rights of the child, 1989. Available: https://www. ohchr.org/en/professionalinterest/pages/crc.aspx
22 General Comment No. 4: adolescent health and development in the context of the convention on the rights of the child, 2003UN Committee on the Rights of the Child (CRC). Available: https:// www.refworld.org/docid/4538834f0.html [Accessed 31 August 2021].

23 WHO. HIV and adolescents: guidance for HIV testing and counselling and care for adolescents living with HIV. Geneva: World Health Organization, 2013.

24 WHO. Guideline on HIV self-testing and partner notification: supplement to consolidated guidelines on HIV testing services. Geneva: World Health Organization, 2016.

25 Hatzold K, Gudukeya S, Mutseta MN, et al. HIV self-testing: breaking the barriers to uptake of testing among men and adolescents in sub-Saharan Africa, experiences from STAR demonstration projects in Malawi, Zambia and Zimbabwe. J Int AIDS Soc 2019;22 Suppl 1:e25244

26 Pettifor A, Lippman SA, Kimaru L, et al. HIV self-testing among young women in rural South Africa: a randomized controlled trial comparing clinic-based HIV testing to the choice of either clinic testing or HIV self-testing with secondary distribution to Peers and partners. EClinicalMedicine 2020;21:100327.

27 Indravudh P, Sibanda E, d'Elbée M. 'I will choose when to test, where I want to test': investigating young people's preferences for HIV selftesting in Malawi and Zimbabwe. AIDS 2017;31:S2013-212.

28 UNAIDS, United Nations Joint Programme on HIV/AIDS. UNAIDS laws and policies analytics, 2020. Available: http://lawsandpolicies. unaids.org/about

29 Fonner VA, Sands A, Figueroa C, et al. Country adherence to WHO recommendations to improve the quality of HIV diagnosis: a global policy review. BMJ Glob Health 2020;5:e001939.

30 Torres MA, Gruskin S, Buse K, et al. Monitoring HIV-related laws and policies: lessons for AIDS and global health in agenda 2030. AIDS Behav 2017;21:51-61.

31 Jamil M, Eshun-Wilson I, Tea CW. Effectiveness of HIVST distribution models in the general population in SSA: a systematic review. In International Conference on AIDS and STIs in Africa 2019:2-7.

32 United States Food and Drug Administration. OraQuick® in-home HIV test summary of safety and effectiveness. Washington, DC: United States Food and Drug Administration, 2012.

33 Staveteig S, Croft TN, Kampa KT, et al. Reaching the 'first 90': Gaps in coverage of HIV testing among people living with HIV in 16 African countries. PLoS One 2017;12:e0186316.

34 Ministerio da Saude. Normas de Tratamento Antirretroviral. República De Angola: Ministerio da Saude, 2015.

35 Directives Nationales de Traitment Antiretrovirale de L'Infection par le VIH au Burundi. Republique du Burundi: Ministre de la Sante Publique et de la Lutte Contre Le Sida 2014.

36 National guideline on the prevention and management of HIV in Cameroon. Government of the Republic of Cameroon: Ministry of Public Health 2015.

37 Procedimentos, normas e direcrizes do atendimento das pessoas que vivem com o virus da immunodeficiencia humana, Cabo Verde: Direcao-Geral de Saude, Programa de Luta Contra a SIDA/IST, Tuberculose e Lepra 2005.

38 Manuel de formation en counseling VIH/SIDA/IST. Republic du Tchad: Ministere de la Sante Publique 2011.

39 Guide de prise en charge de l'infection VIH aux Comores. Union des Comores: Vice Présidence en charge du Ministère de la Santé, de la Solidarité 2007.

40 Guide de prise en charge integree du VIH en Republique Democratique du Congo. Gouvernement de la République Démocratique du Congo: Ministere de la Sante Publique 2017.

41 Cadre strategique national de lutte contre le SIDA 2018-2022. Guinea Conakry, Guinea Comite National de Lutte Contre le SIDA, Secretariat Executif 2018

42 National guidelines for HIV prevention treatment and care. Government of Nigeria: Federal Ministry of Health 2016.

43 National consolidated HIV testing services guidelines. Government of Sudan: Federal Ministry of Health 2016

44 Handbook of the Botswana 2016 integrated HIV clinical care guidelines. Government of the Republic of Botswana: Ministry of Health 2016.

45 National guidelines on the use of antiretroviral therapy for HIV prevention and treatment. Government of Lesotho: Ministry of Health 2016.

46 Directriz nacional para a implementação do aconselhamento e testagem em saúde: República de Moçambique, Ministério a Saúde, Direcção Nacional de Assistência Médica, PNC ITS/HIV/SIDA 2015.

47 National guidelines for prevention and management of HIV and STIs. Government of the Republic of Rwanda: Ministry of Health 2016. 
48 National HIV testing services: policy 2016. Government of the Republic of South Africa: Department of Health 2016.

49 Swaziland integrated HIV management guidelines. Government of the Kingdom of eSwatini: Ministry of Health 2018.

50 Consolidated guidelines for prevention and treatment of HIV in Uganda. Republic of Uganda: Ministry of Health 2016.

51 National Policy Guidelines on HIV AND AIDS. Government of Gambia: National AIDS Council 2014

52 Malawi HIV Tetsing services guidelines. Government of Malawi: Ministry of Health 2016.

53 Integrated guidelines for prevention, testing, care and treatment of HIV and AIDS in Liberia. Republic of Liberia: Ministry of Health 2015.

54 National guidelines for antiretroviral therapy. Government of the Republic of Namibia: Ministry of Health and Social Services 2016.

55 National guidelines for comprehensive HIV prevention, care and treatment. Government of Ethiopia:federal Ministry of health 2017.

56 Kenya HIV testing services guidelines. Kenya: Ministry of Health, National AIDS Control Programme 2015.

57 Politique, Normes et Protocoles des services Depistage Du VIH. Republique du Sénégal: Ministere de la Sante Publique 2017.

58 Somalia HIV testing and counseling policy. Federal Republic of Somalia, Ministry of Health 2017.

59 UNAIDS. United Republic of Tanzania lowers age of consent for HIV testing. Geneva: United Nations Joint Programme on HIV/ AIDS, 2019. https://www.unaids.org/en/resources/presscentre/ featurestories/2019/november/united-republic-of-tanzania-lowersage-of-consent-for-hiv-testing

60 Directives technique de prevention du SIDA et de pris en charge de personnes vivant avec le VIH en Côte d'Ivoire. République de Côte d'Ivoire: Ministere de la Sante et de l'Hygiene 2019.

61 Differentiated service delivery for HIV in Ghana: an operational manual. Government of the Republic of The Gambia: National AIDS Control Programme 2017.

62 HIV testing services national guidelines. Republic of Zambia: Ministry of Health 2016.

63 Guidelines for antiretroviral therapy for the prevention and treatment of HIV in Zimbabwe. Zimbabwe: Ministry of Health and Child Care 2018.
64 Strategie nationale de demedicalisation du Depitage du VIH au Benin. Benin. 2017.

65 Normes et directives nationales de conseil depistage de l'infection a $\mathrm{VIH}$ au Burkina Faso. Gouvernement de Burkina Faso: Ministere de la Sante 2008.

66 Guide du depistage et conseil du VIH la l'initiative du orestataire. Gouvernement de la Republic Centrafricaine: Ministere de la Sante Publique 2010.

67 Eritrea national guidelines for HIV esting services. State of Eritrea: Ministry of Health, Deptartment of Public Health, Communicable Diseases Control Division, National AIDS Control Program 2019.

68 Counseling et Depistage Du VIH a Madagasca Rnormes et procedures. Republic of Madagascar: Le Ministre de la Santé Publique, Programme National de Lutte Contre le SIDA 2011.

69 Normes et procedures des services de Despistage du VIH au Mali. Mali: Haut Conseil National de Lutte Contre le SIDA 2017.

70 Guidelines for HIV testing services in Sierra Leone. Sierra Leone: Ministry of Health and Sanitation: National AIDS Control Programme 2017.

71 Consolidated clinical guidelines on use of antiretroviral drugs for HIV treatment and prevention. Government of the Republic of South Sudan: Ministry of Health 2017.

72 Directives nationales d'utilisation des antiretroviraux pour la prevention et le traitement du VIH: Gouvernement de la Republique du Burundi: Ministere de la Sante 2016.

73 Document de Politique,Normes et Procedures des Services de Depistage du VIH en Côte D'ivoire. Le gouvernement de Côte d'Ivoire: Ministère en charge de la Santé et de l'Hygiene Publique 2016.

74 National HIV and AIDS policy. Republic of Mauritius 2010.

75 National guidelines for the management of HIV and AIDS. Government of the United Republic of Tanzania: Ministry of Health, Community Development, Gender, Elderly, and Children 2017.

76 Lesotho national policy \& guidelines on HIV testing services. Lesotho: Ministry of Health. 2017.

77 Guidelines for antiretroviral therapy for the prevention and treatment of HIV in Zimbabwe. Zimbabwe: Ministry of Health and Child Care 2016. 